\title{
The use of complementary and alternative medicine by patients suffering from psoriasis and psoriatic arthritis
}

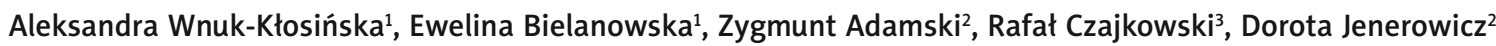 \\ ${ }^{1}$ Student Research Group of Dermatology and Venerology, Poznan University of Medical Sciences, Poznan, Poland \\ 2Department of Dermatology, Poznan University of Medical Sciences, Poznan, Poland \\ ${ }^{3}$ Chair of Dermatology, Sexually Transmitted Diseases and Immunodermatology, Faculty of Medicine in Bydgoszcz, \\ Nicolaus Copernicus University in Torun, Poland
}

Adv Dermatol Allergol 2021; XXXVIII (3): 421-426

DOI: https://doi.org/10.5114/ada.2020.92570

\begin{abstract}
Introduction: Psoriasis is a chronic inflammatory disease, affecting 1-3\% of the general population. In recent years there has been an increase in the use of complementary and alternative medicine (CAM) by psoriasis patients. Aim: To assess the frequency of use of CAM by psoriasis patients, depending on selected demographic and clinical factors, and to examine such aspects as sources of knowledge about CAM therapies provided by patients, reasons for their use, and subjective patient satisfaction.

Material and methods: The study involved 117 psoriatic patients (female $=44$, male $=73$ ), hospitalised in the Dermatology Department of the Heliodor Swiecicki Clinical Hospital in Poznan. The research tool was the author's questionnaire, consisting of single- and multiple-choice questions about the use of CAM.

Results: $57.26 \%$ of the respondents declared that they used or had used CAM for psoriasis. The analysis showed that the patients with psoriasis diagnosed in childhood statistically significantly more often used CAM compared to other patients $(p=0.017)$. The most frequent CAM therapies used by the responders were the use of topical agents $(73.13 \%)$ and dietary supplements $(71.64 \%)$. The main reason why psoriasis patients decided to use CAM was curiosity (34.33\%), and the most commonly reported source of knowledge about CAM was the Internet (49.25\%). The majority of responders monthly expenditure on CAM averaged less than PLN 100 (58.2\%), and they were very dissatisfied with the effects of CAM (56.7\%).

Conclusions: Psoriasis patients use complementary and alternative medicine quite frequently. Dermatologists should keep this fact in mind and should ask about the use of CAM in interviews.
\end{abstract}

Key words: psoriasis, complementary and alternative medicine.

\section{Introduction}

Psoriasis is one of the most common skin diseases. It is estimated to affect $1-3 \%$ of the general population, and in Poland about 800,000 people suffer from it [1, 2]. The disease has a chronic, inflammatory nature and is characterised by the presence of red, scaly plaques with a predilection for limb extensor surfaces and scalp [3].

It is also estimated that psoriatic arthritis affects about $5-30 \%$ of all patients with psoriasis. The exact aetiology of psoriasis is not known yet. However, recent studies have shed new light on the pathomechanism of psoriasis and its comorbidities, and played their part in introducing new therapies [1].
However, despite significant progress in the field of knowledge about the disease and rapid development of anti-psoriatic medications, a significant number of patients still seem to be dissatisfied with the forms of treatment offered, particularly due to their side effects and ineffectiveness [3].

In recent years, more attention has been devoted to the use of complementary and alternative medicine (CAM) by psoriasis patients.

The National Centre for Contemporary and Integrative Health $(\mathrm{NCClH})$ defines contemporary and alternative medicine (CAM) as "a group of diverse medical and health care systems, practices, and products that are not currently considered to be part of conventional

Address for correspondence: Dorota Jenerowicz, Department of Dermatology, Poznan University of Medical Sciences, 49 Przybyszewskiego St, Poznan, Poland, e-mail: djenerowicz@yahoo.com Received: 11.01.2020, accepted: 13.01.2020. 
medicine" [4]. CAM therapies used in psoriasis include, among others, dietary supplements, nutritional modifications, herbal therapies, and mind/body interventions [5]. Several research studies revealed an increase in the use of CAM by patients suffering from psoriasis [6]. However, the guidelines set by the Scientific Society on the treatment of psoriasis do not include any information on the use of CAM [1, 7]. Moreover, in May 2015 the Standing Committee of European Doctors (CPME) presented their position on complementary and alternative treatments. In their view, complementary and alternative practices as well as trainings in this field cannot be considered as part of medicine $[8,9]$.

\section{Aim}

The aim of the study was to assess the frequency of use of CAM by psoriasis patients, depending on selected demographic and clinical factors. We have also examined such aspects as sources of knowledge about CAM therapies provided by patients, reasons for their use, and subjective patient satisfaction.

\section{Material and methods}

The study involved 117 psoriatic patients (44 females and 73 males) (both hospitalised and outpatient) of the Dermatology Department of Poznan University of Medical Sciences.

The average age of the study participants was 48 \pm 12.6 years. The criteria that had to be met in order to be included in the study were age over 18 years and established diagnosis of psoriasis. Participation in the study was voluntary. The research tool was the author's questionnaire consisting of single- and multiple-choice questions about the use of CAM.

\section{Statistical analysis}

Calculations and statistical analysis were carried out with Statistica version 13.3 PL software. Descriptive statistics were calculated for the collected data. To compare differences between groups the $\chi^{2}(2 \times 2$ contingency table $)$ for categorical variables was used. Quantitative variables were compared using the Mann-Whitney $U$ test because the data did not follow normal distribution. The results were considered statistically significant if $p<0.05$.

\section{Results}

Of the respondents $57.26 \%$ (67 out of 117 ) declared that they used or had used CAM to treat psoriasis. The frequency of CAM seemed not to depend on sex, coexistence of psoriatic arthritis, or family history of psoriasis. Patients with childhood psoriasis statistically significantly more often used CAM compared to other patients ( $p=0.017)$ (Table 1). Mann-Whitney's estimate showed no statistically significant difference in age $(p=0.823)$ and duration of disease $(p=0.205)$ between CAM users and CAM non-users (Table 2). The type of CAM used by psoriasis patients was analysed. The most frequent CAM therapies mentioned by the respondents were the use of topical agents (73.13\%) and dietary supplements (71.64\%). Among topical agents, the greatest number of respondents reported the use of cannabis-based preparations (23.88\%) as well as herbal bath blends (22.39\%). Among dietary supplements, herbal supplements were most commonly used (56.72\%). 16.42\% of the respondents admitted that they use diets, while a few individuals used energy healing therapy (Table 3). The main reasons why psoriasis patients decided to use CAM were: curiosity (34.33\%), good product reviews (31.34\%), and ineffectiveness of conventional treatment (31.34\%) (Table 4). As the sources of knowledge about CAM, the respondents most often reported the Internet (49.25\%) and information obtained from other patients with psoriasis (41.79\%). Only individual people listed doctors as their source of knowledge about CAM (4.48\%) (Table 5). The average monthly expenditure on CAM among psoriasis patients was also put into the analysis. Most of the respondents (58.2\%) said that it was less than PLN 100 , while for $4.5 \%$ it was greater than PLN 1000 (Figure 1). $56.7 \%$ of the respondents were very dissatisfied with the effects of CAM. $3 \%$ were satisfied and $3 \%$ were very satisfied (Figure 2).

\section{Discussion}

According to the Polish Dermatological Society, current guidelines for psoriasis treatment emphasise the progress in the treatment of this dermatosis in recent years and the increasing availability of preparations for systemic use.

Psoriasis treatment varies depending on its severity. Mild psoriasis vulgaris includes cases in which less than $10 \%$ of the total body surface area (BSA $<10 \%$ ) is covered by skin lesions, the psoriasis area severity index (PASI) used to access their severity is less than 10, and the quality of patients' lives is moderately affected by the disease (Dermatology Life Quality Index-DLQI score < 10).

The primary treatment for psoriasis is topical therapy. Most commonly used topical medications include calcipotriol in combination with betamethasone, glucocorticosteroids, dithranol, retinoids, calcineurin inhibitors, tars, and keratolytic preparations. In cases when psoriatic lesions cover larger areas of the skin, topical therapy may be supplemented with phototherapy [1]. Moderate to severe psoriasis vulgaris is diagnosed when a patient scores 10 or more in at least one of the tests (BSA, PASI, DLQI). These patients may benefit from phototherapy and photochemotherapy, classic systemic treatment (methotrexate, cyclosporine A, acitretin), and contemporary therapeutic methods, i.e. biologics and new small molecule substances (apremilast, dimethyl fumarate) [7]. 
Table 1. CAM usage, by gender and selected clinical features

\begin{tabular}{|c|c|c|c|c|c|c|}
\hline \multirow[t]{3}{*}{ Feature } & & \multicolumn{4}{|c|}{ CAM usage } & \multirow[t]{3}{*}{ Test $\chi^{2}$} \\
\hline & & \multicolumn{2}{|c|}{ Yes } & \multicolumn{2}{|c|}{ No } & \\
\hline & & $N$ & $\%$ & $N$ & $\%$ & \\
\hline \multirow[t]{2}{*}{ Gender } & Women & 29 & 65.91 & 15 & 34.09 & \multirow{2}{*}{$\begin{array}{l}p=0.142 \\
\chi^{2}=2.153\end{array}$} \\
\hline & Men & 38 & 52.05 & 35 & 47.95 & \\
\hline \multirow[t]{2}{*}{ Psoriatic arthritis } & Yes & 18 & 54.55 & 15 & 45.45 & $p=0.709$ \\
\hline & No & 49 & 58.33 & 35 & 41.67 & $\chi^{2}=0.138$ \\
\hline \multirow[t]{2}{*}{ Psoriasis in the family } & Yes & 28 & 59.57 & 19 & 40.43 & $p=0.679$ \\
\hline & No & 39 & 55.71 & 31 & 44.29 & $\chi^{2}=0.171$ \\
\hline \multirow{2}{*}{$\begin{array}{l}\text { Psoriasis diagnosed in } \\
\text { childhood }\end{array}$} & Yes & 24 & 75.00 & 8 & 25.00 & $p=0.017$ \\
\hline & No & 43 & 50.59 & 42 & 49.41 & $\chi^{2}=5.661$ \\
\hline
\end{tabular}

Table 2. Comparison of groups of patients with psoriasis who use or do not use CAM, by age and duration of the disease (medians, minimal, and maximal values). MannWhitney test

\begin{tabular}{lccc}
\hline Parameter & $\begin{array}{c}\text { CAM users } \\
(n=67)\end{array}$ & $\begin{array}{c}\text { CAM non-users } \\
(n=50)\end{array}$ & $P$-value \\
\hline Age & 43 & 42 & 0.823 \\
& $28-70$ & $18-60$ & \\
\hline Disease uration & 14 & 15 & 0.205 \\
[years] & $0.5-53$ & $0.5-48$ & \\
\hline
\end{tabular}

The aforementioned diagnostic and therapeutic recommendations of the Polish Dermatological Society do not include any information on the use of CAM $[1,7]$. In addition, according to the CPME, when using CAM, doctors are required to inform patients about the nature of CAM and any potential risks it entails.

Furthermore, patients who decide to use CAM and inform their doctors about it must receive unbiased information on the nature of such treatment. The important fact that should also be kept in mind by physicians is that some groups of patients (patients with cancer, psychiatric conditions, severe chronic illnesses, and children) are particularly susceptible to possible risks of using CAM. In such cases, doctors should consider using CAM together with patients' existing medical treatment. The CPME emphasises the fact that only treatments that are proven to be effective and safe should be funded by public health care budgets $[8,9]$.

However, despite the wide range of conventional treatment options, the frequency of CAM usage for psoriasis is reported to oscillate between $42 \%$ and $69 \%$ [5].

In our study, $57.26 \%$ of psoriasis patients declared that they used or had used CAM.

Nevertheless, what should be kept in mind is that it is uncertain exactly how frequently CAM is used, because patients tend not to let doctors know that they have used it. This may be due to their assumptions that the physicians will react negatively to such information,
Table 3. CAM methods chosen by patients with psoriasis

\begin{tabular}{|c|c|}
\hline Methods & $N(\%)$ \\
\hline Dietary supplements & $48(71.64)$ \\
\hline Herbal: & $38(56.72)$ \\
\hline Primrose preparations & $19(28.36)$ \\
\hline Flaxseeds & $4(5.97)$ \\
\hline Cistus incanus & $4(5.97)$ \\
\hline Other & $16(23.88)$ \\
\hline Vitamins: & $12(17.91)$ \\
\hline Vit. A & $7(10.45)$ \\
\hline Vit. D & $6(8.96)$ \\
\hline Vit. C & $2(2.99)$ \\
\hline Vit. B & $2(2.99)$ \\
\hline Omega 3 fatty acids & $4(5.97)$ \\
\hline Mānuka honey & $3(4.48)$ \\
\hline Other & $6(8.96)$ \\
\hline Diets & $11(16.42)$ \\
\hline Topical agents: & 49 (73.13) \\
\hline Herbal bath blends & 15 (22.39) \\
\hline Calendula ointments/creams & $9(13.43)$ \\
\hline The Dead Sea mud and salt & $8(11.94)$ \\
\hline Cannabis-based preparations & $16(23.88)$ \\
\hline $\begin{array}{l}\text { Olive and unrefined (coconut, linseed, } \\
\text { hemp) Oils mixtures }\end{array}$ & $14(20.90)$ \\
\hline Yeast mixtures & $7(10.45)$ \\
\hline Aloe creams & $3(4.48)$ \\
\hline Other & $12(17.91)$ \\
\hline Energy healing therapy & $3(4.48)$ \\
\hline Other & $29(43.28)$ \\
\hline
\end{tabular}

The number of responses is not equal to the number of people using CAM $(n=67)$ because it was a multiple-choice question. 
Table 4. The main reasons why patients with psoriasis use CAM (distribution by gender)

\begin{tabular}{|c|c|c|c|c|c|c|}
\hline \multirow[t]{2}{*}{ Reason } & \multicolumn{2}{|c|}{ Women } & \multicolumn{2}{|c|}{ Men } & \multicolumn{2}{|c|}{ All } \\
\hline & $N$ & $\%$ & $N$ & $\%$ & $N$ & $\%$ \\
\hline Ineffectiveness of conventional treatment & 11 & 37.93 & 10 & 26.32 & 21 & 31.34 \\
\hline High costs of conventional treatment & 1 & 3.45 & 3 & 7.90 & 4 & 5.97 \\
\hline Good product reviews & 6 & 20.69 & 15 & 39.47 & 21 & 31.34 \\
\hline Curiosity & 9 & 31.04 & 14 & 36.84 & 23 & 34.33 \\
\hline Convictions about safety of natural products & 7 & 24.14 & 8 & 21.05 & 15 & 22.39 \\
\hline Willingness to support conventional treatment & 0 & 0.00 & 3 & 7.90 & 3 & 4.48 \\
\hline Other & 1 & 3.45 & 2 & 5.26 & 3 & 4.48 \\
\hline
\end{tabular}

The number of responses is not equal to the number of people using CAM $(n=67)$ because it was a multiple-choice question.

Table 5. Sources of knowledge about CAM in patients with psoriasis (distribution by gender)

\begin{tabular}{|c|c|c|c|c|c|c|}
\hline \multirow[t]{2}{*}{ Source } & \multicolumn{2}{|c|}{ Women } & \multicolumn{2}{|c|}{ Men } & \multicolumn{2}{|c|}{ All } \\
\hline & $N$ & $\%$ & $N$ & $\%$ & $N$ & $\%$ \\
\hline Internet & 13 & 44.83 & 20 & 52.63 & 33 & 49.25 \\
\hline The press & 1 & 3.45 & 4 & 10.53 & 5 & 7.46 \\
\hline TV & 2 & 6.90 & 2 & 5.26 & 4 & 5.97 \\
\hline Information from other patients with psoriasis & 12 & 41.38 & 16 & 42.11 & 28 & 41.79 \\
\hline Doctor & 1 & 3.45 & 2 & 5.26 & 3 & 4.48 \\
\hline Other & 4 & 13.79 & 4 & 10.53 & 8 & 11.94 \\
\hline
\end{tabular}

The number of responses is not equal to the number of people using CAM $(n=67)$ because it was a multiple-choice question.

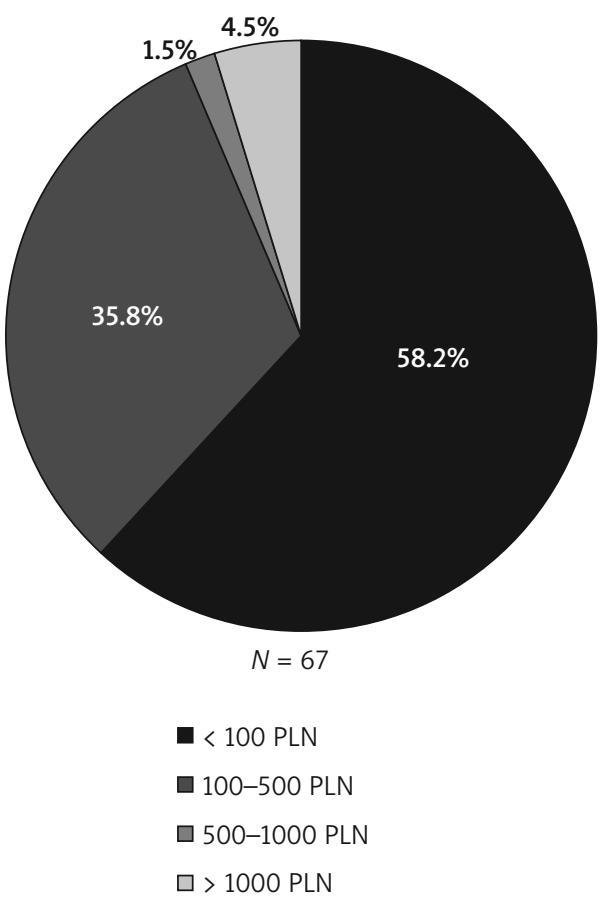

Figure 1. Monthly expenditure on CAM among patients with psoriasis

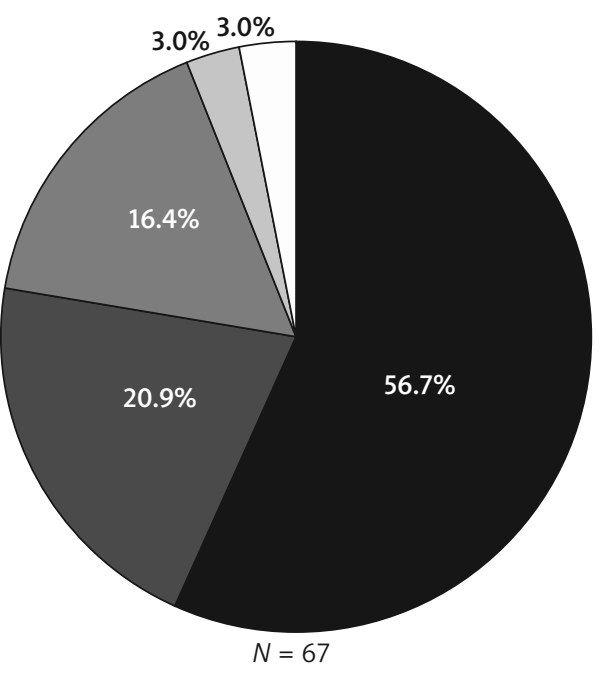

- Very dissatisfied

- Dissatisfied

$\square$ Moderately satisfied

$\square$ Satisfied

$\square$ Very satisfied

Figure 2. Satisfaction with CAM effects among patients with psoriasis 
or due to their beliefs that the use of plant and herbal medicine is inappropriate [6].

This phenomenon may be important in relation to potential side effects caused by CAM. In a study conducted by Clark et al. on a group of 50 patients with psoriasis, some patients suffered adverse effects from CAM. The side effects were typical of the alternative therapies and included vomiting and diarrhoea [10]. Damevska et al. point out that in their study a small number of the patients (5.8\%) took oral herbal mixtures the composition of which was unknown. Such practice may lead to the use of potentially toxic species and drug-herb interactions. Contact allergy may be caused by marigold (Calendula officinalis), propolis, and aloe vera products [6].

Patients ought to consult their doctors before they begin to use any herbal supplements. Special caution should be taken when a patient is considering taking both a herbal medication and a prescription medication with a narrow therapeutic index, such as anticoagulants, anti-diabetic drugs, antineoplastics, digoxin, and immunosuppressants [5].

In the study conducted by Murphy et al. women with psoriasis used CAM statistically more often than men [11]. Our statistical analysis did not show a significant difference in the frequency of CAM use between sexes. However, patients with psoriasis diagnosed in childhood appeared to be more frequent users of CAM than other psoriasis patients. CAM is usually used as a 'complementary' therapy rather than an 'alternative' therapy. Most patients use CAM along with traditional treatment to get, as they believe, the best results. Some other reasons for CAM usage are: preferences for natural treatment methods, assumptions about a reduced amount of side effects, and lack of satisfaction with the effectiveness and toxicity of conventional medicine [5].

In the study by Murphy et al., when asked why they use CAM, the respondents most often gave the following reasons: ineffectiveness of traditional medicines, avoidance of side effects from traditional medicines, and preference for natural ingredients typical of CAM [11].

In our survey, the respondents indicated curiosity, good product reviews and ineffectiveness of conventional treatment as the most common reasons for using CAM.

In the study by Clark et al., patients with psoriasis admitted that they received most of the information about CAM from mass media, friends and relatives, and their own 'experience'. For 10 patients, CAM was recommended by other psoriasis patients and for three by healthcare professionals. The median estimated amount of money

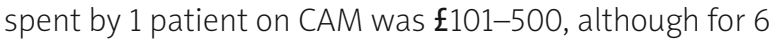
patients it was $\mathfrak{£ 1 0 0 0}$ [10].

In this study, as a source of knowledge about CAM, the respondents most often reported the Internet and information obtained from other patients with psoriasis. Only individual patients mentioned doctors as their source of knowledge about CAM. 58.2\% of the respondents said that the average monthly expenses for CAM were less than PLN 100, while for $4.5 \%$ they were greater than PLN 1000.

Murphy et al. asked 218 people with psoriasis whether they would recommend CAM to other people with psoriasis. $42.66 \%$ of the respondents answered yes, $18.81 \%$ answered no, and $38.53 \%$ were unsure [11]. In our survey, $56.7 \%$ of the respondents were very dissatisfied with the effects of CAM, whereas $6 \%$ were satisfied or very satisfied.

A systematic review of 57 trials and three meta-analyses carried out by Caresse Gamret et al. showed that indigo naturalis, curcumin, dietary modification, fish oil, meditation, and acupuncture appeared to be the most effective in the treatment of plaque psoriasis [3]. In their review of CAM efficacy, Talbott et al. also point to the effectiveness of some herbal therapies (Mahonia aquifolium and indigo naturalis), fish oil, mind/body interventions, and Dead Sea climatotherapy [5].

What should be highlighted is that CAM is widely used by patients in different fields of medicine, and its use is constantly growing. According to the National Centre for Complementary and Integrative Health $(\mathrm{NCCIH}), \mathrm{CAM}$ is most commonly used by American adults for musculoskeletal problems [4]. Augustyniuk et al. showed in their study the frequent use of CAM by patients with cancer, who were undergoing chemotherapy [12]. In the study by Hung et al. 269 out of all patients with gastrointestinal diseases (44\%) declared the use of CAM [13]. See et al. demonstrated in their study that CAM was widely used by patients with psoriasis, but also in various other dermatoses, among others, acne, eczema, and alopecia [14].

However, it should be emphasised that, regardless of the field of medicine, people should be discouraged from using any medications with unclear composition. Considering the widespread use of CAM by patients and the potential side effects, especially from products with an unknown composition, doctors should include questions about CAM usage in the clinical interview. Appropriate patient education in this topic is also necessary [6].

\section{Conclusions}

Psoriasis patients use complementary and alternative medicine quite frequently. It seems that the use of CAM does not depend on sex, co-morbidity of psoriatic arthritis, a family history of psoriasis, age, and duration of the disease. Patients with psoriasis diagnosed in childhood took CAM more often than the rest of the patients with psoriasis. Among psoriasis patients, the most frequently used CAMs were diet supplements (mainly herbal), topical preparations (mainly Cannabis-based), and herbal bath blends. The primary reasons for CAM usage were curiosity, good product reviews, and ineffectiveness of conventional treatment. The vast majority of CAM users 
were very dissatisfied or dissatisfied with the effectiveness of CAM. Dermatologists should keep in mind the fact that psoriasis patients use CAM frequently, and they should ask about the use of CAM in the interviews.

\section{Conflict of interest}

The authors declare no conflict of interest.

\section{References}

1. Reich A, Adamski Z, Chodorowska G, et al. Psoriasis. Diagnostic and therapeutic recommendations of the Polish Dermatological Society. Part I: Mild psoriasis. Dermatol Rev 2018; 105: 225-43.

2. Włodarczyk J, Knyszyńska A, Lubkowska A. Quality of life in patients with psoriasis. J Educ Health Sport 2019; 9: 203-11.

3. Gamret AC, Price A, Fertig RM, et al. Complementary and alternative medicine therapies for psoriasis. JAMA Dermatol 2018; 154: 1330-7.

4. National Center for Complementary and Alternative Medicine. The Use of Complementary and Alternative Medicine in the United States. Available from: URL: https://nccih.nih. gov/research/statistics/2007/camsurvey_fs1.htm\#about. Accessed November 19, 2019.

5. Talbott W, Duffy N. Complementary and alternative medicine for psoriasis: what the dermatologist needs to know. Am J Clin Dermatol 2015; 16: 147-65.

6. Damevska K, Neloska L, Nikolovska S, et al. Complementary and alternative medicine use among patients with psoriasis. Dermatol Ther 2014; 27: 281-3.

7. Reich A, Szepietowski J, Adamski Z, et al. Psoriasis. Diagnostic and therapeutic recommendations of the Polish Dermatological Society. Part II: Moderate to severe psoriasis. Dermatol Rev 2018; 105: 329-57.

8. http://doc.cpme.eu:591/adopted/2015/CPME AD Board 23052015 FINAL EN.CPME.Statement.on.alternative. treatments.FINAL.23.05.2015.Reykjavik.pdf. Accessed December 18, 2019.

9. https://nil.org.pl/aktualnosci/komplementarne-i-alternatywne-metody-leczenia-stanowisko-cpme. Accessed December 18, 2019.

10. Clark CM, Mckay RA, Fortune DG, Griffiths CE. Use of alternative treatments by patients with psoriasis. Br J Gen Pract 1998; 48: 1873-4.

11. Murphy EC, Nussbaum D, Prussick R, Friedman AJ. Use of complementary and alternative medicine by patients with psoriasis. J Am Acad Dermatol 2019; 81: 280-3.

12. Augustyniuk K, Brudnoch K, Owsianowska J, et al. The use of alternative and complementary medicine practices by cancer chemotherapy patients. Fam Med Prim Care Rev 2016; 18: 7-11.

13. Hung A, Kang N, Bollom A, et al. Complementary and alternative medicine use is prevalent among patients with gastrointestinal diseases. Dig Dis Sci 2015; 60: 1883-8.

14. See A, Teo B, Kwan R, et al. Use of complementary and alternative medicine among dermatology outpatients in Singapore. Austral J Dermatol 2011; 52: 7-13. 